\title{
The intonation of Italian verbless exclamatives
}

Patrizia Sorianello

Department of Letters, Language, Arts, University of Bari, Italy

https://doi.org/10.36505/ExLing-2020/11/0049/000464

\begin{abstract}
The present study aims to explore the prosodic properties of Italian verbless exclamatives (VEs), particular sentence structures without wh-quantifier and copula. A speech corpus formed by 250 VEs uttered by five subjects of a Southern variety of Italian was analyzed. The experimental results proved that VEs have a marked prosodic structure typically made up by two opposed constituents. The preposed predicative phrase is characterized by a salient intonation contour, while the grammatical subject is marginalized and shows a monotonous $\mathrm{f0}$ pattern. The information structure is fixed too: the predicative constituent carries the new information, thus contrasting with the subject that expresses a given content.
\end{abstract}

Keywords: intonation, verbless exclamatives, Italian language

\section{Introduction}

Verbless exclamatives (from now VEs) are a particular type of sentence attested in diverse Romance languages used to express strong personal opinions. They are verbless configurations in which the ellipsis of the verb (normally the copula) produces reduced utterances with or without the wh-modifier, i.e. Che buona questa torta! (What a good cake!), Buona, questa torta! (Good, this cake!). This sentence structure shows a series of syntactic, information and prosodic restrictions. VE has a rigid syntactic order: the predicative complement precedes the grammatical subject of the clause since it is placed in the left periphery of the sentence. The order of the constituents is fixed and cannot be changed, *Questa torta, buona! (*This cake, good!). Moreover, in Italian the anteposed complement may be occupied only by gradable and evaluative adjectives, noun and adjective or, in alternative, by a noun preceded by an indefinite article i.e. Una bontà, questa torta! (A goodness, this cake.). If present, the initial wh-word is always 'che' (what), being impossible the presence of other wh-modifiers ( ${ }^{*}$ Come buona questa torta!, *How good this cake.), while the predicate must contain a personal emotional reaction, in line with the property of factivity, a peculiar semantic property of exclamatives. At the same time, the subject of the sentence holds demonstratives or deictic determiners, for this reason it does not allow indefinite lexical forms, *Buona, una torta! ( ${ }^{*}$ Good, a cake!).

As far as the information structure is concerned, VEs can never be considered neutral utterances. The predicative phrase conveys the information focus of the sentence, since it represents the unit which is informatively

ExLing 2020: Proceedings of $11^{\text {th }}$ International Conference of Experimental Linguistics, 12-14 October 2020, Athens, Greece 
relevant; in other words it expresses a widening and extreme-degree meaning, two intrinsic properties of exclamatives. On the contrary, the subject transmits a presupposed meaning.

There are diverse studies focused on the syntactic and semantic properties of VEs (Vinet, 1991; Gutierrez-Rexach 2001; Zanuttini \& Portner 2003; Munaro, 2016), but the prosody of VEs has not received much attention so far. Narrowing the attention to the Italian language, some information can be deduced from Munaro (2016), while a detailed spectro-acoustic analysis is available in Sorianello (2017).

\section{Methodology}

This research intends to investigate the intonation contours of Italian VEs adopting an acoustical perspective. For this study we considered only VEs lacking of verb (silent copula) and of wh-word (silent che) in which the predicative complement has an adjectival nature i.e. Interessante, questo libro! (Interesting, this book.). The language under investigation is a Southern variety of Italian (Cosenza). Five participants aged between 22 and 30 ( 3 F, 2 M) were involved in a reading task. They produced 50 VEs embedded in short scenarios purposely constructed to simulate appropriate pragmatic contexts. Each target sentence was compared with both assertive (ASs) and wh- versions (wh-Es). The total corpus consisted of 250 VEs (50 sentences for 5 speakers), 250 whEs and 250 ASs (ie. Buona, questa torta $\$ Che buona è questa torta $\backslash$ Questa torta è buona). Audio recordings were acoustically analyzed with PRAAT by means of the following parameters: $\mathrm{fO}$ maximum, $\mathrm{fO}$ minimum, average $\mathrm{f0}$, pitch range (in semitones), speech rate (sill/sec), duration of stressed vowels. Pitch accents and boundary tones were individuated on the f0 curve and labelled according to ToBI. Statistical significance was tested by Anova $(\mathrm{p}<0.05)$.

\section{Results and discussion}

The intonation contours of all target sentences are falling (L\%). Nevertheless, their realization is different. VEs have a final falling pitch pattern which does not overlap that of wh-Es or ASs, being characterized by a greater pitch range, a higher $\mathrm{f} 0$ initial value and a different intonational phrasing. The height of the initial f0 contributes to differentiate VEs from ASs; this phonetic cue plays a crucial role in the realization of a VE since it emphasizes the speaker-based evaluation. With reference to intonation, it is significant to observe that the pattern of VEs is formed by two opposed phases separated by an intermediate accent. The initial constituent is always salient: it shows a wide pitch range (in average 8 ST, SD: 2) and high values of intensity. The predicative complement is the only prominent portion of the sentence and receives the most salient

pitch accent. In line with its expressive meaning, the preposed adjectival constituent presents an extra-high level $\left(\mathrm{H}^{*}\right.$ or $\left.\mathrm{L}+\mathrm{H}^{*}\right)$ followed by a steep fall 
that ends with a low intermediate accent (L-). On the contrary, the remaining part, syntactically coincident with the marginalized subject, always shows a low intonation contour ( $\mathrm{L}^{*} \mathrm{~L} \%$ ) and a compressed pitch excursion (in average 3 ST, SD: 1) without considerable movement within the stressed vowel; the intonation configuration is illustrated in Figure 1.

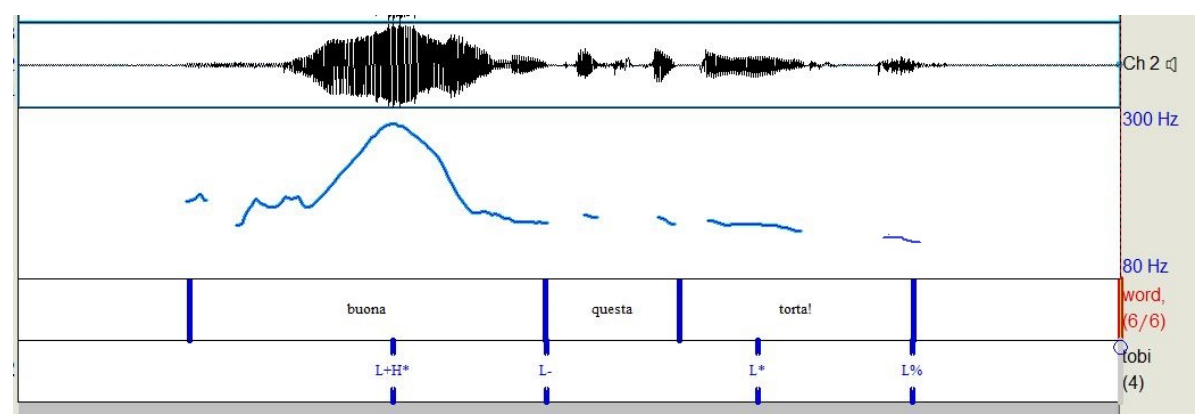

Figure 1. Waveform and $\mathrm{f} 0$ pattern of the VE Buona questa torta! realized by a female speaker.

As far as duration is concerned, the initial phrase is significantly longer in VEs than in control sentences; nuclear vowels are longer too, respectively VEs: 200 ms (SD: 38), wh-Es: $170 \mathrm{~ms}$ (SD: 35), ASs: $150 \mathrm{~ms}$ (SD: 22), all the statistical comparisons are significant $(\mathrm{p}<.005)$. This result is not surprising, in VEs the predicative complement, together with the deletion of the copula, causes a rhythmic and prosodic fracture. The adjective that conveys the focus of the exclamation shows a significant lengthening, a peculiar aspect that increases its unexpected content: the greater the sense of unexpectedness, the greater the degree of lengthening. The exclamatory force is not only given by the presence of longer nuclear vowels, but also by a general speech slowing; the results regarding speaking rate confirm this impression. VEs display a slow speaking rate, medially 4.8 sill/sec (SD: 0.5) whereas ASs and wh-Es reach the mean rate of 7 sill/sec (SD: 0.6) and 5.6 (SD: 0.7) respectively; the differences are statistically significant $(\mathrm{p}<.005)$.

The information structure of VEs is rigid too. It can be represented as follows:

$$
\text { Buona }_{\text {NEW }} \text { questa torta! GIVEN }
$$

The order is fixed: the predicative complement coincides with the NEW information, the subject with the GIVEN one. Prominence is the result of the interaction of several factors. The information focus receives prosodic salience; all the acoustic parameters are activated in an 'extra' way making the predicative constituent longer, more intense and with a greater pitch excursion. All this ensures the realization of the widening meaning of the exclamative contributing, at the same time, to the achievement of an adequate exclamatory 
force. The adjectival constituent conveys the surprising and emotional content of the sentence, since it expresses an evaluation at an extreme point of a scale. On the contrary, the subject is marginalized and represents old information; it refers to something which is already present in the common ground of the participants. Accordingly, it is produced with no accentuation: a flat intonational contour $\left(\mathrm{L}^{*}\right.$ or $\left.! \mathrm{H}+\mathrm{L}^{*}\right)$ placed on the lowest $\mathrm{f} 0$ range characterized it. The boundary between the two constituents is obligatory signalled by a low phrase accent (L-). In general, information and prosodic structures establish a strong relationship: the predicative phrase and the subject one show in fact a polarized behaviour for duration, speaking rate, intensity, pitch range and intonation contour. The marked position of the predicative constituent has deep effects on the other levels. It transmits a high degree of emotional arousal, but also a new information. The surprising content is limited only to the first part of the VE, a condition reinforced also by the lack of both the wh-word and the copula; as a consequence, the final region of the utterance is totally deaccented.

This study added new data to the prosodic description of VEs. The analysis showed that in Italian VEs are rigid sentential structures formed by two constituents distinguished by opposite information and prosodic features. This peculiar organization is perfectly congruent with their pragmatic and expressive content.

\section{References}

Gutiérrez-Rexach, J. 2001. Spanish exclamatives and the interpretations of the left periphery. In D’Hulst, Y., Rooryck, J. \& Schroten, J. (eds.), Romance languages and linguistic theory 1999, Amsterdam/Philadelphia, J. Benjamins, 167-194.

Munaro, N. 2016. Verbless predicative structures across Romance. Journal of Linguistics 52, 609-637.

Rett, J. 2008. A degree account of exclamatives. In Friedman T. \& S. Ito (eds.) Proceedings of SALT XVIII, Ithaca, New York, CLC Publications, 601-608.

Sorianello, P. 2017. Sulla realizzazione prosodica delle esclamative nominali. Rivista Italiana di Dialettologia 41, 147-170.

Vinet, M. T. 1991. French non-verbal exclamative constructions. Probus 3, 77-100.

Zanuttini, R., Portner, P. 2003. Exclamative clauses: at the syntax-semantics interface. Language 79, 39-81. 